\title{
Thoracic surgery milestones 2.0: Rationale and revision
}

\author{
Brian Mitzman, MD, ${ }^{\mathrm{a}}$ Jared P. Beller, MD, ${ }^{\mathrm{b}}$ and Laura Edgar, EDD, CAE
}

In 1999, the American Board of Medical Specialties and Accreditation Commission for Graduate Medical Education (ACGME) jointly approved 6 core competencies aimed at providing a framework for developmental areas important for physicians in training. These were later launched as part of the Outcomes Project in 2001. ${ }^{2}$ The aim of this joint project was to improve the quality of graduate medical education through the avoidance of overspecialization while providing key developmental areas relevant to all specialties. The competencies include patient care and procedural skills, medical knowledge, professionalism, systems-based practice, interpersonal and communication skills, and practice-based learning and improvement. ${ }^{3,4}$

However, when first introduced, programs struggled with overall implementation of the competencies into individual training pathways and their application to different specialties. Many were unsure how to appropriately integrate the competencies into already-used evaluation models. In 2009, the ACGME introduced Milestones as part of the Next Accreditation System. ${ }^{5}$ To build on the initial competencies, subcompetencies were selected addressing a specific disease or discipline specific element. Milestones were developed as individual elements for each subcompetency. These milestones included a trajectory for a trainee to follow throughout their growth, with specific examples for the trainee's specialty. The expectation was that programs would identify and implement a variety of tools to assess their trainee's progress in acquiring these milestones. The actual tools used were left to the discretion of the programs. Twice each year, programs were required to report to the ACGME the progress their trainees were making in achieving their milestones. The ACGME is now in the process of updating the milestones as part of the Milestones 2.0 project. Thoracic Surgery is among the first subspecialty groups to near completion of the process. In the following, we describe the foundation

\footnotetext{
From the a Department of Cardiothoracic Surgery, NYU Langone Health, New York, NY; ${ }^{\mathrm{b}}$ Department of Surgery, University of Virginia, Charlottesville, Va; and ${ }^{\mathrm{c}} \mathrm{Ac}-$ creditation Council for Graduate Medical Education, Chicago, Ill.

Source of funding: Accreditation Council for Graduate Medical Education (ACGME).

Received for publication Nov 4, 2019; revisions received Nov 25, 2019; accepted for publication Dec 6, 2019; available ahead of print March 31, 2020.

Address for reprints: Brian Mitzman, MD, NYU Langone Health, 259 1st St, Mineola, NY 11501 (E-mail: brian.mitzman@nyulangone.org).

J Thorac Cardiovasc Surg 2020;160:1399-404 0022-5223/ $\$ 36.00$

Copyright (c) 2020 Published by Elsevier Inc. on behalf of The American Association for Thoracic Surgery

https://doi.org/10.1016/j.jtcvs.2019.12.132
}

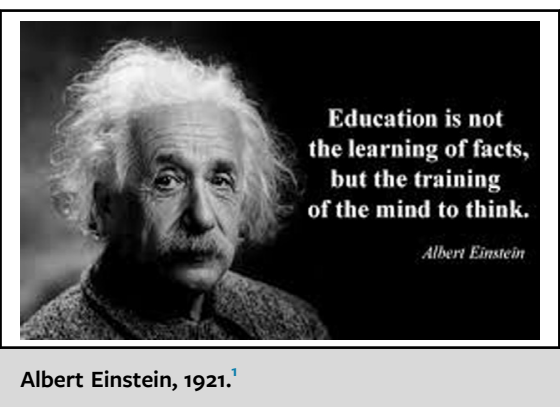

$$
\begin{aligned}
& \text { CENTRAL MESSAGE } \\
& \text { Thoracic Surgery Milestones } 2.0 \\
& \text { are being developed to } \\
& \text { strengthen resident assessment } \\
& \text { and training. }
\end{aligned}
$$

See Commentaries on pages 1405 and 1406.

for this work with the history of the initial milestone development and ongoing work for Milestones 2.0.

\section{HISTORY OF THORACIC SURGERY MILESTONES 1.0}

A working group was formed in January of 2012 by the American Board of Thoracic Surgery (ABTS) and ACGME. ${ }^{6}$ It was widely accepted that due to recent changes in curriculum and training of cardiothoracic surgery residents, Milestone development was coming at an opportune time. The initial working group was made up of academic thoracic surgeons with specific interest in resident education. Initially chaired by Dr Carolyn Reed, this group represented all areas of adult cardiac, general thoracic, and congenital heart surgery. An advisory group was created to oversee the working group's progress and had representative leaders from the ABTS, ACGME, and Thoracic Surgery Resident Association.

The initial charge of the working group was to design Thoracic Surgery Milestones that could be used to evaluate traditional 2 and 3 year training programs, 4/3 training models, and also the new 6-year integrated residency programs. Throughout 2012, the milestones were developed through conference calls and several in person meetings at the ACGME headquarters in Chicago.

Integrating Milestone competencies with the ABTS curriculum, the working group chose to categorize the Medical 
Knowledge and Patient Care/Technical Skills competencies into organ systems. This aligned with the diverse knowledge and skill sets required for the varied aspects of cardiothoracic surgery training. In total, 25 milestones were developed. ${ }^{7}$ The completed Thoracic Surgery Milestones were first presented to the Thoracic Surgery Directors Association at the Society of Thoracic Surgeons and American Association of Thoracic Surgeons meetings in 2013.

Beta-testing of the Milestones began in 2013 at selected thoracic surgery programs. Overall, the Milestones were well received and pilot programs felt that there was appropriate discriminatory ability of Milestone progression to identify competency needed for the completion of training. While it was expected that graduating trainees reached level 4 of 5 for all milestones, these were meant to be used only as a reporting tool rather than summative assessment involved in credentialing or certification. It was left to the discretion of the individual programs to determine how to assess and rate each resident, and the subsequent scores would not specifically be used for promotion or graduation criteria. The milestones were rolled out nation-wide to all programs during the 2014 to 2015 academic cycle. During the development of the Milestones, the ACGME had committed to a review and revision process for 3 to 5 years after implementation. ${ }^{8}$ Version 1.0 was meant to be an implementation, and not the final product.

\section{VARIABILITY AMONG THE SPECIALTY SPECIFIC SUBCOMPETENCIES AND MOTIVATION FOR HARMONIZED MILESTONES}

Although the Milestones were initially created as an adjunct to the ACGME Competencies, the resulting specialty-specific milestones led to substantial variability between specialties. This was evident both with respect to content as well as how the development progression was operationalized across milestone levels. ${ }^{9}$ At the 2nd ACGME Milestones Summit in December of 2016, stakeholders expressed dissatisfaction with the variability among specialties and inconsistencies within the different milestones. It was noted that these differences had "complicated efforts to share assessment tools across programs, and provide comprehensive faculty development across specialties." It was concluded that these differences may hamper, rather than encourage, collaboration in assessment and faculty development across specialties counter to the initial intent over a when these frameworks were first developed.

To address these concerns, the ACGME Department of Research, Milestone Development, and Evaluation formalized a plan for the review and revision process. This work began in 2016 with a review of data collected from the field, the data submitted for the twice-yearly milestone reporting, and learning from quantitative and qualitative research. ${ }^{10}$ It was expected that there may be significant variability in Medical Knowledge and Patient Care Milestones, but more consistency was needed in the other domains expected to be conserved among specialties programs. This became the motivation for the Harmonized Milestones. To date, more than 300 peer-reviewed studies about the milestones have been completed, and a bibliography of milestone research is available on the ACGME website.

The development of the Harmonized Milestones used both quantitative and qualitative data. The quantitative research demonstrated the need and fit for key components of the milestones in several specialties. Qualitative research has focused on program directors' and trainees' experience with the milestones, Clinical Competency Committee processes, the value of milestone-based feedback, and milestone design. A thematic analysis of the milestones for the non-Patient Care and non-Medical Knowledge domains confirmed wide variation among specialties. The analysis showed that across the 26 core specialties and the transitional year there were more than 230 different ways of describing Professionalism, 171 for Practice-Based Learning, 176 for Interpersonal and Communication Skills, and 122 for Systems-Based Practice. ${ }^{11}$ This early research on the milestones has helped inform the milestone revision process.

To address the inconsistency in non-Medical Knowledge and Patient Care Milestones, in 2016, the ACGME convened 4 groups to develop cross-specialty "harmonized" milestones for Interpersonal and Communication Skills, Practice-Based Learning, Professionalism, and Systems-Based Practice. The 4 groups consisted of content experts, directors, interprofessional team members, and other faculty. Each group developed 2 to 3 subcompetencies that were applicable to all specialties and subspecialties, which are now the basis for the Harmonized Milestones used by all specialties in for the Milestones 2.0. These were built with the intention that language in these harmonized milestones could be modified as needed to pertain to each specific subspecialty during the working group 2.0 development, although the intent was to keep the overall concept identical between specialty milestones.

\section{THORACIC SURGERY MILESTONES 2.0 DEVELOPMENT}

The need for revision of the milestones was based on multiple criteria, including research, focus groups, and feedback sent directly to the ACGME. ${ }^{12}$ This was further informed by ACGME Milestone staff attendance at more than 200 program director meetings, focus groups, and visits to accredited programs in an attempt to gather feedback. These meetings helped to outline the revision process 
for Milestones 2.0 which focused on 4 categories, including (1) selection of the Milestone groups, (2) reduction of Milestone complexity, (3) enhancing community engagement, and (4) providing additional tools and resource for programs and sponsoring institutions. ${ }^{11}$ While most subspecialties have found the milestones to be a useful assessment tool, a common theme with the limitations has been administrative burden, training of faculty for appropriate assessment, and subjective evaluation of surgical aptitude. ${ }^{13-16}$ A new Thoracic Surgery working group was formed to guide this development (Figure 1).

The Milestones 2.0 working group for Thoracic Surgery includes representatives from the ACGME Thoracic Surgery Review Committee, ABTS, Thoracic Surgery Directors Association, volunteers from the thoracic surgery community, current trainees, and a public member

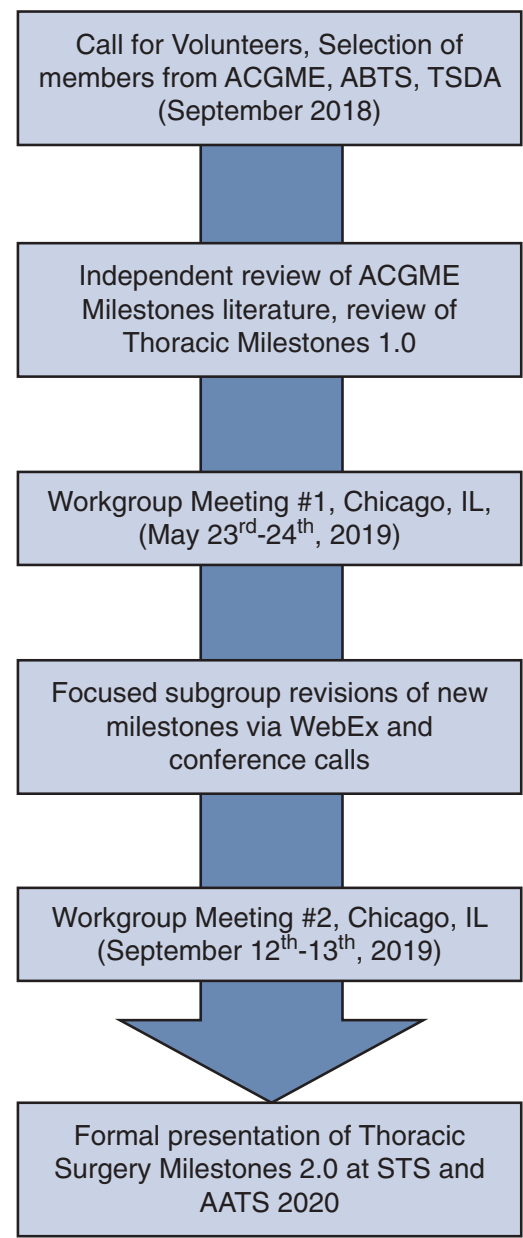

FIGURE 1. Steps of development for Thoracic Surgery Milestones 2.0. ACGME, Accreditation Commission for Graduate Medical Education; ABTS, American Board of Thoracic Surgery; TSDA, Thoracic Surgery Directors Association; STS, Society of Thoracic Surgeons; AATS, American Association of Thoracic Surgeons.
(Table 1). The group begin by reviewing data, program requirements, ABTS curriculum guidelines, and certification blueprints.

The next step focused on simplification of the Thoracic Surgery Milestones 2.0. A Supplemental Guide has been created with 1 to 2 examples for each level. These are not meant to be specific criteria for attaining a specific level. They are designed to be a guide for the individual program director in determining the complexity of knowledge and skills required to attain that level. Further, many milestones have descriptions for disease processes and procedures including "routine," "complex," and "advanced." Again, it is left up to the individual program director to decide what constitutes one of these categories. Supplemental tables developed by the working group are available for increased guidance, providing specific procedures, complications, and disease processes representative of differing levels of complexity. An example of the changes made from version 1.0 to 2.0 is provided in Figure 2.

Currently, Thoracic Surgery Milestones 2.0 has been reduced to 24 from 26 subcompetencies. The Patient Care and Medical Knowledge competencies are broken down in an attempt to appropriately separate all major aspects of cardiothoracic surgery training. Patient Care now includes Ischemic Heart Disease, Mechanical Circulatory Support, Valvular Disease, Great Vessel Disease, Esophagus, Lung and Airway, Chest Wall/Pleura/Mediastinum/Diaphragm, Critical Care, and a Technical Skills for General Surgery Category meant for integrated residents. Medical Knowledge has been divided into Cardiovascular, General Thoracic, and Congenital Heart Disease (Table 2).

Along with consideration for simplicity and efficiency, the development group considered what changes the graduate of 2025 might experience. The field of cardiothoracic surgery and medicine in general is rapidly changing and we had to deliberate new technologies, like transcatheter aortic valve replacement, robotics, telemedicine, and the overall health care system. This brainstorming activity helped the group determine a final set of sub competencies that the public will expect from every physician.

\section{INTENDED USE: SELF-ASSESSMENT, CLINICAL COMPETENCY COMMITTEE REVIEW, AND SUPPLEMENTAL GUIDE}

Use of the new milestones will begin in the 2020 to 2021 academic year. Each program should complete several activities in early summer 2020 . The first will be a thorough review of the new supplemental guide. The supplemental guide will include several features to aid programs and clinical competency committees (CCC) in their understanding 
TABLE 1. Members of the Thoracic Surgery Milestone 2.0 Working Group

- Jared Beller, MD, University of Virginia

- Kathleen K. Berfield, MD, University of Washington Medicine

- Luther Brewster, PhD, Florida International University

- David A. Bull, MD, University of Arizona Health Sciences

- Jonathan D'Cunha, MD, PhD, University of Pittsburgh

- Laura Edgar, EdD, ACGME

- Jordan Hoffman, MD, Vanderbilt University Medical Center

- Ann Hwalek, DO, Loyola University Medical Center

- Taryne A. Imai, MD, Cedars-Sinai Medical Center

- Shari Meyerson, MD, University of Kentucky

- Brian Mitzman, MD, NYU Langone Health

- Paul H Schipper, MD, Oregon Health \& Science University

- Frederick A. Tibayan, MD, Oregon Health \& Science University

- Ara A. Vaporciyan, MD, MHPE, University of Texas MD Anderson Cancer Center

- Thomas Varghese, MD, MS, University of Utah

- Stephen C. Yang, MD, Johns Hopkins Medical Institutions and assessment of milestones. The development group explains the intent of each subcompetency and provides examples for each of the individual milestones. There are also suggested assessment models and tools and resources for the subcompetency.

Each program must review the milestones and their current assessment tools. It is not expected that each program will revamp their method of assessment. However, programs will need to ensure that the new milestones can be evaluated with their current assessment tools and make changes where required. Ideally, for each resident, all milestones will have the opportunity for several evaluations by multiple evaluators every 6 months. In recognizing that this is not always possible, each program should ensure the broadest assessment feasible.

Once the assessment tools are identified, the CCC should meet to create a shared mental model around the new milestones. This is an accepted concept when discussing

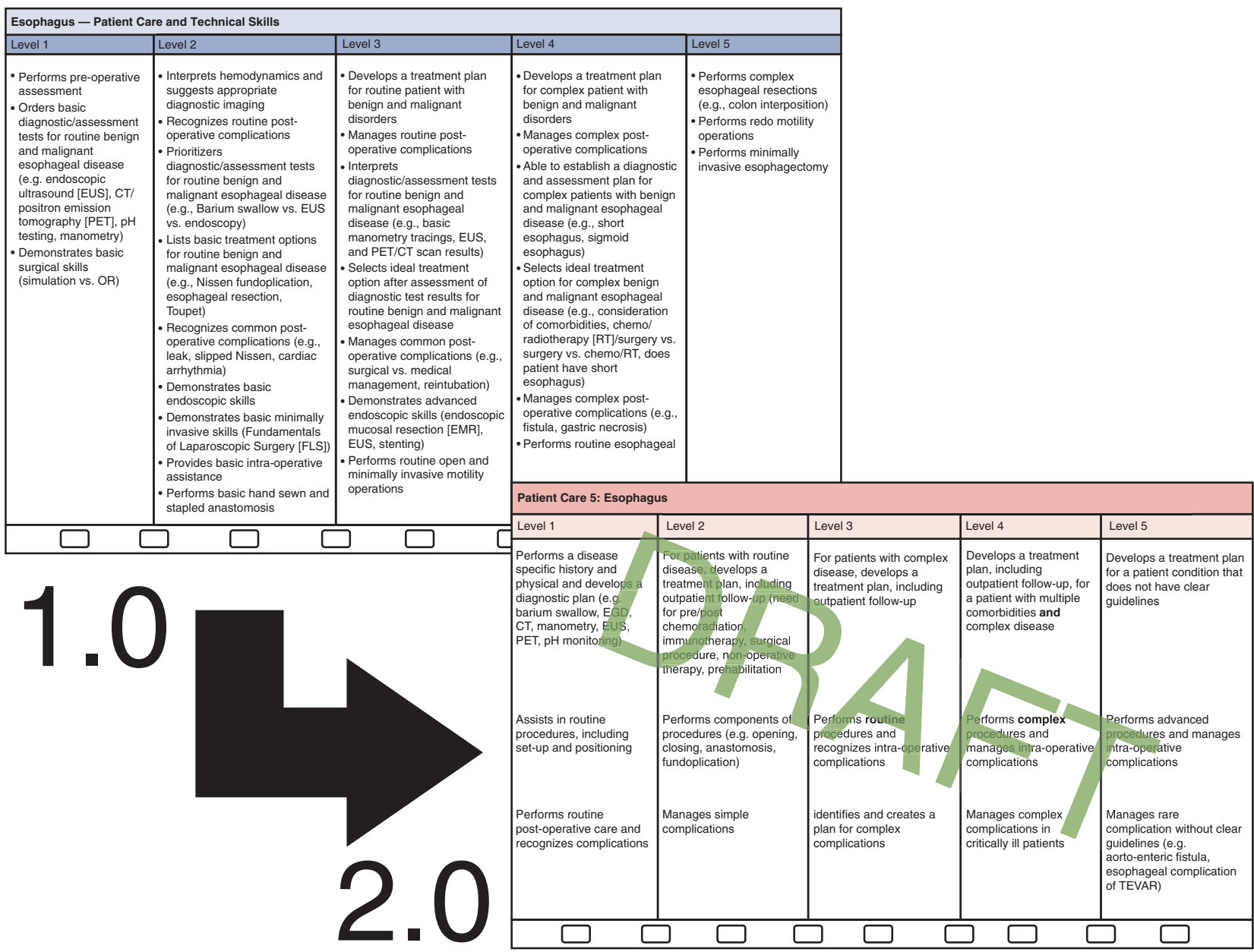

FIGURE 2. Example of changes seen from version 1.0 to 2.0 of Patient Care and Technical Skills for esophagus. CT, Computed tomography; EUS, endoscopic ultrasound; $E G D$, esophagogastroduodenoscopy. 
TABLE 2. Milestone distribution across the 6 competencies

\begin{tabular}{|c|c|c|c|c|c|}
\hline \multicolumn{2}{|c|}{ Specialty-specific } & \multicolumn{4}{|c|}{ Harmonized } \\
\hline PC & MK & SBP & PBLI & Prof & ICS \\
\hline Ischemic Heart Disease & $\begin{array}{l}\text { Cardiovascular } \\
\text { Knowledge }\end{array}$ & $\begin{array}{l}\text { Patient Safety and } \\
\text { Quality Improvement }\end{array}$ & $\begin{array}{l}\text { Evidence-Based and } \\
\text { Informed Practice }\end{array}$ & Ethical Principles & $\begin{array}{l}\text { Patient and Family-Centered } \\
\text { Communication }\end{array}$ \\
\hline $\begin{array}{l}\text { Mechanical Circulatory } \\
\text { Support }\end{array}$ & $\begin{array}{l}\text { General Thoracic } \\
\text { Knowledge }\end{array}$ & $\begin{array}{l}\text { System Navigation for } \\
\text { Patient-Centered Care }\end{array}$ & $\begin{array}{l}\text { Reflective Practice and } \\
\text { Commitment to } \\
\text { Personal Growth }\end{array}$ & $\begin{array}{l}\text { Professional } \\
\text { Behavior and } \\
\text { Accountability }\end{array}$ & $\begin{array}{l}\text { Interprofessional and Team } \\
\text { Communication }\end{array}$ \\
\hline Valvular Disease & $\begin{array}{l}\text { Congenital Heart } \\
\text { Disease }\end{array}$ & $\begin{array}{l}\text { Physician Role in } \\
\text { Health Care Systems }\end{array}$ & & $\begin{array}{l}\text { Administrative } \\
\text { Tasks }\end{array}$ & $\begin{array}{l}\text { Communication within } \\
\text { Health Care Systems }\end{array}$ \\
\hline Great vessel Disease & & & & Well-Being & \\
\hline Esophagus & & & & & \\
\hline Lung and Airway & & & & & \\
\hline $\begin{array}{l}\text { Chest Wall, Pleura, } \\
\text { Mediastinum, Diaphragm }\end{array}$ & & & & & \\
\hline Critical Care & & & & & \\
\hline $\begin{array}{l}\text { Technical Skills for General } \\
\text { Surgery (Integrated Only) }\end{array}$ & & & & & \\
\hline
\end{tabular}

teamwork among humans. It relates to improved performance and efficiency when all team members have shared understanding of the goals for a project and subsequent work required. ${ }^{17}$ The CCC should review each subcompetency, determine their expectations for each level, and document their decisions. The primary reason for each CCC to complete this activity is the context in which the residents are trained is different for every program. By completing the exercise, the CCC can begin each meeting with a shared decision making model allowing for more time to be spent discussing the resident's next stages in the program.

Assessment is an activity expected of all faculty. Most have not had training on the assessment tools they are using. It is recommended that the shared mental model exercise should also be completed using the various assessment tools. This exercise should include all faculty. Verify that the faculty are looking at the same activity in the same way and identifying the same actions in a similar manner. When assessments are disparate, the resident is unable to use the information for improvement and the CCC has a more difficult time evaluating the milestones.

Another element is resident self-assessment with the milestones. The residents should complete the selfassessment each time the CCC is going to meet. The program director, or other faculty member, who shares the CCC results with the resident can compare both sets of assessment with the resident. This comparison is helpful for both the program and the resident. The program will have insight into the resident's understanding of their knowledge, skills, and attitudes (KSA). The resident will learn to calibrate their awareness of these same KSAs. This calibration will aid the resident when they enter practice, as they must learn to assess their own KSAs with new techniques and treatments that will be developed.

\section{NEXT STEPS}

The next step for Thoracic Surgery Milestones 2.0 will be a review by the members of the Thoracic Surgery Directors Association, ABTS, and Thoracic Surgery Residency Administrators and Coordinators, along with faculty, residents, and the public. Formal review of the milestones will be launched in January 2020. The milestones will be presented at the 2020 Annual Meetings of the Society of Thoracic Surgeons and American Association for Thoracic Surgery. Feedback to the ACGME and the Thoracic Surgery Working Group will be exceptionally important during this time period. When you receive the survey, please share it with your colleagues and residents. This is an important opportunity to influence the milestones. Once the milestones are finalized, programs should start planning a review with the $\mathrm{CCC}$, faculty, and residents and create a shared mental model.

\section{CONCLUSIONS}

The ACGME is in the midst of a specialty-by-specialty revision of the Milestone project intended to improve on the foundation created when they were initially launched. We present an outline of the history of the Milestones project, rationale and methodology for the 2.0 revision, and plans for its implementation. This revision includes critical 
improvements aimed at improving usability, minimizing complexity, and enhancing consistency with other specialties. As the milestones continue to mature, the plan for the next formal revision will be in 7 to 10 years. However, the milestones 2.0 will be monitored frequently and a means for continuous feedback has been developed. The Milestone framework continues to broadly remain the same, but has been adapted to ensure that the milestones continue to be an effective tool for the assessment of residents and fellows across all specialties.

\section{Conflict of Interest Statement}

Dr Beller is a Member of the ACGME Milestones Committee. All other authors have nothing to disclose with regard to commercial support.

\section{References}

1. Frank P, Rosen G, Kusaka S. Einstein: His Life and Times. New York: A. A. Knopf; 1947.

2. Swing SR. The ACGME outcome project: retrospective and prospective. Med Teach. 2007;29:648-54.

3. Batalden P, Leach D, Swing S, Dreyfus H, Dreyfus S. General competencies and accreditation in graduate medical education. An antidote to over specification in the education of medical specialists. Health Aff. 2002;21:103-11.

4. IOM (Institute of Medicine). Graduate Medical Education That Meets The Nation's Health Needs. Washington, DC: The National Academies Press; 2014.

5. Nasca TJ, Philibert I, Brigham T, Flynn TC. The Next ACGME accreditation system-rational and benefits. N Engl J Med. 2012;366:1051-6.

6. Yang SC, Merrill W. Educational milestone development in phase II specialties: thoracic surgery. J Grad Med Educ. 2014;6:329-31.
7. The thoracic surgery milestone project. J Grad Med Educ. 2014;6(1 suppl 1): 332-54.

8. Holmboe ES, Yamazaki K, Edgar L, Conforti L, Yaghmour N, Miller RS, et al. Reflections on the first 2 years of milestone implementation. J Grad Med Educ. 2015;7:506-11.

9. Leep Hunderfund AN, Reed DA, Starr SR, Havyer RD, Lang TR, Norby SM. Ways to write a milestone: approaches to operationalizing the development of competence in graduate medical education. Acad Med. 2017;92:1328-34.

10. Sangha S, Hamstra SJ. Milestones Bibliography. ACGME. Available at: https:// www.acgme.org/Portals/0/PDFs/Milestones/MilestonesBibliography_June 2019 Final.pdf?ver=2019-07-31-160132-843. Accessed January 3, 2020.

11. Edgar L, Roberts S, Yaghmour N, Hunderfund AL, Hamstra SJ, Conforti L, et al. Competency crosswalk: a multispecialty review of the Accreditation Council for Graduate Medical Education milestones across four competency domains. Acad Med. 2018;93:1035-41.

12. Edgar L, Roberts S, Holmboe E. Milestones 2.0-a step forward. J Grad Med Educ. 2018;6:367-9.

13. Peabody MR, O'Neill TR, Peterson LE. Examining the functioning and reliability of the family medicine milestones. J Grad Med Educ. 2017;9: 46-53.

14. Ross FJ, Metro DG, Beaman ST, Cain JG, Dowdy MM, Apfel A, et al. A first look at the accreditation council for graduate medical education anesthesiology milestones: implementation of self-evaluation in a large residency program. J Clin Anesth. 2016;32:17-24.

15. Beeson MS, Holmboe ES, Korte RC, Nasca TJ, Brigham T, Russ CM, et al. Initial validity analysis of the emergency medicine milestones. Acad Emerg Med. 2015; 22:838-44.

16. Bortoletto HE, Barnes KL, Kaimal AJ, Stagg AR. Resident and program director's perceptions of milestone-based feedback in obstetrics and gynecology. $J$ Med Educ Curric Dev. 2018;5. 2382120518774794.

17. Jonker CM, van Riemsdijk MB, Vermeulen B. Shared mental models. In: De Vos M, Fornara N, Pitt JV, Vouros G, eds. Coordination, Organizations, Institutions, and Norms in Agent Systems VI. COIN 2010. Lecture Notes in Computer Science. Berlin, Heidelberg: Spring; 2011:6541. 